\title{
Further observations on social dominance in mice'
}

\author{
G. LINDZEY, D. THIESSEN, S. BLUM, and A. TUCKER, \\ University of Texas, Austin, Tex. 78712
}

A $/ J$ mice win tube dominance competitions over $\mathrm{C} 3 \mathrm{H} / \mathrm{HeJ}$ and $D B A / 1 J$ mice. This finding corroborates earlier findings using similar measures of dominance but different substrains of these lines. "Directional persistence" affords the explanation for the superiority of the A strain.

Surprisingly little work has been addressed to the problems of assessing individual differences in animal temperament and motivation, and even less attention has been paid to the role of genetic variation in this domain. Several years ago, it was reported by one of us (Lindzey, Winston, \& Manosevitz, 1961) that individual and strain differences in "tube dominance" among mice were highly stable. The behavioral test was quite straight forward. Two individuals of separate inbred strains, selected from $\mathrm{A} /$ alb (A), $\mathrm{C} 3 \mathrm{H}$, and DBA/8 (DBA) strains were individually trained to run through a Lucite tube for a food reward and finally were run simultaneously from the two ends of the tube. When the two mice met in the middle of the tube, a partition was removed and the test for dominance began. The mouse which displaced the other from the tube in the majority of five trials was declared the winner. The rank order dominance relation between the three strains was $\mathrm{A}>\mathrm{C} 3 \mathrm{H}>\mathrm{DBA}$, with As winning $84 \%$ of their competitions with the $\mathrm{C} 3 \mathrm{Hs}$ and $98 \%$ of their bouts with the DBAs. The $\mathrm{C} 3 \mathrm{Hs}$ won $82 \%$ of their duels with the DBAs. In the majority of the competitions, the animals which won the first trial proceeded to win the remaining four trials as well. In another study (Lindzey, Manosevitz, \& Winston, 1966), when measures of dominance based on food competition and paired fighting were used, the order was reversed, the DBAs winning over As. In general, tube dominance correlates negatively with food competition and paired fighting.

Our aim was to determine whether the earlier findings on tube dominance could be replicated using sublines of the strains used previously, and to compare strain differences in dominance with strain differences on various measures of arousal. It was hoped that such a comparison would shed light on the mechanisms underlying dominance behavior in the tube and elsewhere.

\section{METHODS}

Subjects were 20 males from each of three inbred strains of Mus musculus: $\mathrm{A} / \mathrm{J}, \mathrm{C} 3 \mathrm{H} / \mathrm{HeJ}$, and $\mathrm{DBA} / 1 \mathrm{~J}$. Animals were tested between 72 and 127 days of age. The dominance apparatus and procedure were similar to that described by Lindzey et al (1961). A Lucite tube with an inside diameter of $1 \mathrm{in}$. and a length of $17 \mathrm{in}$. was positioned between two goal boxes $4 \times 4$ in. square. Guillotine doors were located at the entrance to each goal box and a Lucite divider could be inserted midway along the tube. The diameter of the tube was sufficiently wide to allow one mouse to move through, but not wide enough to permit two mice to pass one another. General activity was measured in a $20 \times 20$ in. field (arena) lined into 16 squares of equal size. Barriers 5 in. high were positioned upright on the floor at regular intervals. Walls $5 \mathrm{in}$. high surrounded the field, and the entire apparatus was painted gray.

All Ss were isolated beginning 25 days before testing and throughout the experiment. Six days prior to the first dominance test body weights and rectal temperature were recorded. Thereafter, food was provided only in amounts sufficient to maintain the animals at approximately $85 \%$ of their initial body weights.

Pretraining in the tube was conducted during the 4 days preceding and the 1 st day of dominance testing. Animals were run four trials a day through the tube to a reward of wet Purina Laboratory Chow. The direction of running was alternated on successive trials. On Day 5 dominance testing began and continued for 3 consecutive days. Immediately preceding a dominance trial a mouse was placed in each of the two goal boxes. When both reached the center of the tube, the divider was removed and the duel began. The trial ended when one mouse had forced the other to retreat completely into the goal box from which it had started. Ss were immediately removed to prevent fighting.

Competitions occurred within triads, three mice (one from each strain) comprising a triad. Members of a triad were matched on the basis of body weight. On each of 3 days, each animal met every other member of its matched group. The sequence of testing and the starting position were varied in a systematic way. The winner or dominant animal in each pairing, or match, was considered to be the one which won two or more of three competitions. The data obtained from

Table 1

Strain Differences in Tube Dominance

\begin{tabular}{|c|c|c|c|c|c|c|}
\hline \multirow{2}{*}{$\begin{array}{l}\text { Competition: } \\
\text { Winner: }\end{array}$} & \multicolumn{2}{|c|}{$\mathrm{A}$ vs $\mathrm{C} 3 \mathrm{H}$} & \multicolumn{2}{|c|}{ A vs DBA } & \multicolumn{2}{|c|}{$\mathrm{C} 3 \mathrm{H}$ vs DBA } \\
\hline & $\mathbf{A}$ & $\mathrm{C} 3 \mathrm{H}$ & A & DBA & $\mathrm{C} 3 \mathrm{H}$ & DBA \\
\hline $\begin{array}{l}\text { Total trials } \\
\text { won } \\
(\mathrm{N}=51)\end{array}$ & $44(86 \%)$ & $7(14 \%)$ & $36(71 \%)$ & $15(29 \%)$ & $24(47 \%)$ & $27(53 \%)$ \\
\hline $\begin{array}{l}\text { Total matches } \\
\text { won* } \\
(\mathrm{N}=17)\end{array}$ & $16(94 \%)$ & $1(6 \%)$ & $13(76 \%)$ & $4(24 \%)$ & $8(47 \%)$ & $9(53 \%)$ \\
\hline $\begin{array}{l}\text { No. of dominant } \\
\text { Ss winning } \\
\text { all three trials }\end{array}$ & 11 & 0 & 6 & 0 & 3 & 4 \\
\hline $\begin{array}{l}\text { No. of dominant } \\
\text { Ss winning } \\
\text { two trials only }\end{array}$ & 5 & 1 & 7 & 4 & 5 & 5 \\
\hline
\end{tabular}

* $A$ match consisted of the 3 trials between any two Ss. The winner of the match was considered to be the animal which won 2 or more of the competitions. 
Table 2

Comparison of Strain Differences Observed in the Present Experiment and in the Experiment of Lindzey et al (1961)

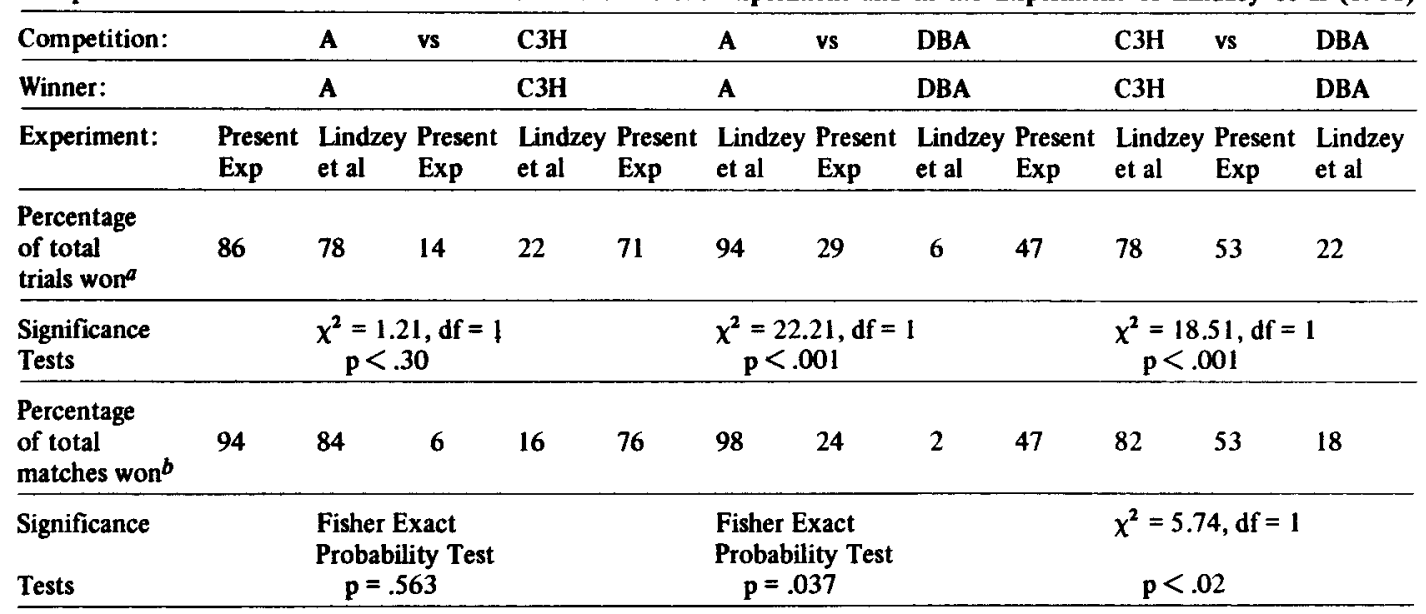

a Percentages for the present experiment based on 51 trials; for that of Lindzey et al, on 220 trials.

$b$ Percentages for the present experiment based on 17 matches; for that of Lindzey et al, on 44 matches.

three of the triads were discarded because of accidents or deaths to one or more animals in these groupings. Thus 17 triads were tested, for a total of 51 matches and 153 trials, or competitions.

On the day dollowing the last competition the arena activity of individual animals was measured by recording the number of line crossings during a $3-\mathrm{min}$ period. The numbers of fecal boli and urine deposits were also recorded. Four days later each $S$ was injected with $135 \mathrm{mg} / \mathrm{kg} d$-amphetamine hydrochloride, and the latencies to convulse and die were recorded. The observation period was $15 \mathrm{~min}$, and if an animal did not seize (or die) during this period, it was given a score of $900 \mathrm{sec}$. Amphetamine injections and all other manipulations were performed in the latter part of the light phase of a 12-h light-dark cycle. The results of dominance tests were compared to those of Lindzey et al (1961) and related to measures of body temperature, locomotor activity, emotionality (defecation and urination), and amphetamine susceptibility.

\section{RESULTS AND DISCUSSION}

Table 1 shows the findings for the dominance testing. As were clearly dominant over $\mathrm{C} 3 \mathrm{Hs}$ and to a lesser degree over DBAs. No dominance relation was evident between $\mathrm{C} 3 \mathrm{Hs}$ and DBAs. Binomial tests revealed that As differed widely from C3Hs and DBAs in both trials won $(p<.00006$ and $p<.005$, respectively) and in total matches won $(p<.0001$ and $\mathrm{p}<.049$, respectively). A significantly higher proportion of As (9 out of 17) than of C3Hs and DBAs ( 3 out of 17 for both strains) defecated during the 3 -min arena test $\left(\chi^{2}=6.80\right.$, $\mathrm{df}=2, \mathrm{p}<.05$ ). The only other measures reaching significance were general activity $(F=42.78, \mathrm{df}=2$ and $48, \mathrm{p}<.001)$, with As showing lower activity than other strains and initial body weight $(\mathrm{F}=7.29, \mathrm{df}=2$ and $48, \mathrm{p}<.01)$, with $\mathrm{C} 3 \mathrm{H}$ animals weighing more than the other strains. Terminal body weight, determined by the deprivation schedule, was of course proportional to the initial weights. In general then, dominant As are characterized by low activity and body weight, and high emotionality. Somewhat surprisingly no differences were found in amphetamine susceptibility.

Our dominance tube results correspond well with those of Lindzey et al (1961) as far as the As are concerned, but not with regard to the relation between the $\mathrm{C} 3 \mathrm{H}$ and DBA strains (see Table 2). Whereas the earlier study found dominance differences between the C3Hs and DBAs, this study did not. The $\mathrm{C} 3 \mathrm{H}$ and DBA strains have many genes in common with each other, but not with the A strain (Staats, 1966). Evidently the substrain differences in the two studies account for the discrepancies.

The adaptive significance of the trait measured by means of tube dominance is uncertain. Relating our findings to those reported earlier (Lindzey et al, 1961, 1966), it would seem that tube dominance is negatively related to food competition and fighting, and is positively associated with low activity and emotionality. Southwick \& Clark (1966) confirm our general observations that As show lower levels of behavioral arousal (open-field activity and bar presses) than either C3Hs or DBAs, and they also note that As tend to lose in fights with other strains. Correlation does not denote casualty, but it does seem that a plodding fearful animal is likely to move slowly but steadily through a tube only to lose in open competition.

Social dominance clearly appears to depend on the genotype of the animals involved but also depends on the circumstances under which it is observed. The tube dominance measure may well be related to persistence, which, under some ecological situations, may be adaptive where assertion in a confined area could lead to increased reproductive fitness.

\section{REFERENCES}

LINDZEY, G., MANOSEVITZ, M., \& WINSTON, H. Social dominance in the mouse. Psychonomic Science, 1966, 5, 451-452.

LINDZEY, G., WINSTON, H., \& MANOSEVITZ, M. Social dominance in inbred mouse strains. Nature, 1961, 191, 474-476.

STAATS, J. Nomenclature. In E. L. Green (Ed.), Biology of the laboratory mouse. New York: McGraw-Hill, 1966. Pp. 45-50.

SOUTHWICK, C. H., \& CLARK, L. H. Aggressive behavior and exploratory activity in fourteen mouse strains. American Zoologist, $1966,6,246$.

NOTE

1. Supported by NIMH Grant No. MH $14076-02$ and by NIMH Research Development Award MH 11, 174-01 to D. Thiessen. A. Tucker's present address is Oklahoma Medical School, Oklahoma City. 